\title{
"Meu Sonho É Ser Compreendido": Uma Análise da Interação Médico-Paciente Surdo durante Assistência à Saúde
}

\author{
"My Dream Is To Be Understood": an Analysis of the Doctor-Deaf \\ Patient Interaction during Health Care
}

\author{
Antonio Augusto Claudio Pereira ${ }^{I}(1)$ \\ Nayara de Paula Passarin ${ }^{I}$ (iD \\ Fernanda Shizue Nishida ${ }^{I}$ (D) \\ Valéria Ferreira Garcez ${ }^{I}$
}

\section{PALAVRAS-CHAVE}

- Acesso aos Serviços de Saúde.

- Atenção à Saúde.

- Comunicação em Saúde.

- Ensino.

- Linguagem de Sinais.

- Relações Médico-Paciente.

- Surdez.

\section{RESUMO}

Introdução: A comunidade surda representa uma importante parcela da população brasileira que enfrenta inúmeras barreiras na acessibilidade à saúde. Falhas de comunicação aumentam as chances de diagnósticos equivocados, erros de prontuário, constrangimentos, não adesão ao tratamento, sofrimento e insatisfação do usuário. Este estudo teve como objetivos caracterizar os atendimentos de saúde aos surdos, na perspectiva dos profissionais médicos, dos internos de Medicina e dos próprios usuários, e discutir as estratégias desenvolvidas na interlocução e interação médico-paciente e as ferramentas para o aprimoramento da prática médica. Método: Trata-se de um estudo observacional, descritivo, com análise integrada de conteúdo. Participaram da pesquisa 181 indivíduos que foram divididos em três grupos: profissionais médicos $(n=46)$, graduandos de Medicina da quinta e sexta séries $(n=54)$ e indivíduos surdos $(n=81)$. Utilizaram-se dois instrumentos semiestruturados: um para médicos e internos e outro para surdos. Realizou-se uma análise descritiva das variáveis quantitativas com distribuições percentuais para variáveis categóricas e medida de tendência central e dispersão para variáveis numéricas. As respostas das questões dissertativas foram organizadas em três corpus textuais relacionados ao sentimento dos profissionais médicos, internos e surdos durante o atendimento. Em seguida, o material foi submetido à análise lexicográfica com auxílio do software IRaMuTeQ. Resultado: Dentre os médicos e acadêmicos, $76 \%$ afirmaram que já atenderam um paciente com surdez grave parcial ou severa. Embora $49 \%$ dos surdos tenham afirmado que já sentiram algum desconforto e também alguma segurança no atendimento, 55,5\% mencionaram que já deixaram de ir ao médico por medo de não serem compreendidos ou relataram algum problema, como dor, desconforto ou angústia. A participação de acompanhantes como mediadores da relação médico-paciente foi a estratégia mais apontada por todos os participantes. Entre os entrevistados surdos, outras estratégias frequentes mencionadas foram leitura labial e Libras; no caso dos médicos, mímica e escrita; em relação aos internos, leitura labial e escrita. Todas as estratégias não são resolutivas. Conclusão: As percepções dos diferentes atores da interação médico-paciente analisados mostraram diferença de satisfação com o serviço e riscos à saúde dos surdos, o que significa que falta planejamento multimodal com estratégias de comunicação efetivas. 


\section{KEYWORDS}

- Health Services Accessibility.

- Health Care.

- Health Communication.

- Teaching

- Sign Language.

- Physician-Patient Relations.

- Deafness.

\section{ABSTRACT}

Introduction: The deaf community represents a significant portion of the Brazilian population that faces numerous barriers in access to health care. Communication failures increase the chances of misdiagnosis, errors in medical records, embarrassment, non-adherence to treatment, suffering and user dissatisfaction. The study aimed to characterize health care for deaf people from the perspective of medical professionals, medical interns and the patients themselves, discussing the strategies developed in the dialogue and physician-patient interaction, and the tools for the improvement of medical practice. Method: An observational, descriptive study based on integrated content analysis. A sample of 181 participants divided into three groups: medical professionals $(n=46)$, medical students from the fifth and sixth year $(n=54)$ and deaf individuals $(n=81)$. Two semi-structured instruments were used, one for doctors and interns and one for the deaf. Descriptive analysis of the quantitative variables was performed with percentage distributions for categorical variables and measure of central tendency and dispersion for numerical variables. The answers to the essay questions were organized into three groups of texts and the material was submitted to lexicographic analysis with the support of IRaMuTeQ software. Results: $76 \%$ of doctors and academics said they had already treated a patient with severe or partial deafness. Although 49\% reported discomfort, but also feeling secure when treating deaf patients, 55.5\% of the deaf said they had already stopped going to the doctor, or reporting any problems, such as pain, discomfort or anguish, for fear of not being understood. The participation of caregivers as mediators of the doctor-patient relationship was the most frequent communicational strategy pointed out by all participants. Other frequent strategies identified by the deaf interviewees were lip reading and LIBRAS; by the doctors, mime and writing; and by the interns, lip reading and writing; all of which are non-resolving strategies. Conclusions: The perceptions of the different actors of the doctor-patient interaction analyzed showed differences in satisfaction with the service and health risks for the deaf, lacking multimodal planning with effective communication strategies.

Recebido em 31/1/20

Aceito em 23/7/20

\section{INTRODUÇÃO}

A assistência médica é guiada por uma anamnese adequada e um exame físico dirigido, os quais norteiam a elaboração de hipóteses diagnósticas e planos terapêuticos. A comunicação é peça-chave nesse processo $^{1}$. Comunicar-se de maneira clara e eficiente no contexto clínico traduz-se num sistema de saúde mais acessível ${ }^{2}$ e eficaz, sendo crucial para a construção de uma boa relação médico-paciente ${ }^{3}$.

Apesar de a Política Nacional de Saúde da Pessoa Portadora de Deficiência, desde 2006, assegurar os direitos dos usuários de saúde surdos, a comunidade surda ainda representa importante parcela da população brasileira que enfrenta inúmeras barreiras na acessibilidade à saúde ${ }^{4}$. Estima-se que 9,7 milhões de brasileiros apresentem algum tipo de deficiência, sendo $22,1 \%$ com caráter severo - isto é, indivíduos que não ouvem ou com baixa audição, ainda que usem aparelhos auditivos ${ }^{5}$. Falhas de comunicação aumentam as chances de diagnósticos equivocados ${ }^{6}$, erros de preenchimento de prontuário por problemas de compreensão na anamnese, constrangimentos, não adesão ao tratamento, sofrimento $\mathrm{e}$ insatisfação do usuário ${ }^{2,6}$.

Embora o Decreto n 5.626 de 2005 garanta à pessoa com deficiência um ambiente preventivo, curativo e reabilitador, ainda assim, quase 15 anos depois, o Sistema Único de Saúde (SUS) apresenta muitos obstáculos para o atendimento de pessoas com deficiência auditiva ${ }^{4,7}$. Esse decreto também determina a obrigatoriedade do ensino da Língua Brasileira de Sinais (Libras) nos cursos de formação para exercício do magistério, de licenciatura e de Fonoaudiologia de instituições brasileiras públicas e privadas. Para o curso de Medicina e os demais cursos de educação superior e profissional, a disciplina deve ser ofertada de forma eletiva ${ }^{8}$.
Independentemente das variáveis implicadas na implantação da disciplina de Libras na graduação, é fato que a acessibilidade no atendimento clínico dos surdos faz-se relevante para a formação holística e integral dos profissionais da saúde ${ }^{6}$.

Sabe-se que o atual encontro clínico entre médico e paciente surdo é, na maioria das vezes, inadequado, limitado pela comunicação deficiente entre os pares, contrapondo-se à acessibilidade esperada ${ }^{9}$. Considerando que a atenção básica é a principal porta de entrada para o SUS, tornase necessário investigar se os profissionais de saúde estão preparados para acolher o surdo nas suas múltiplas necessidades, respeitando sua autonomia e seu direito à promoção da saúde ${ }^{4}$.

Verifica-se que não existem muitos estudos recentes na literatura que se destinam a entender a relação entre os profissionais de saúde e o paciente surdo quanto à acessibilidade em saúde. Alguns trabalhos buscaram descrever a perspectiva dos médicos ${ }^{2,6}$, outros, as percepções de indivíduos com surdez ${ }^{1,9-11}$. Estudos de revisão reuniram trabalhos para fomentar discussões quanto aos obstáculos e às dificuldades enfrentados no atendimento ${ }^{3,4,12-14}$. Entretanto, nenhum estudo abordou as percepções sobre a temática sob a perspectiva de médicos, surdos e graduandos de Medicina, todos atores em um sistema de saúde do mesmo município.

Uma vez que as últimas diretrizes curriculares do curso de Medicina foram aprovadas em 2014, julgamos interessante explorar a ótica dos futuros egressos e verificar se há distinção dos profissionais já inseridos no mercado de trabalho.

Nesse sentido, objetivou-se caracterizar os atendimentos de saúde aos surdos, na perspectiva dos profissionais médicos, dos internos de medicina e dos próprios usuários, e discutir as estratégias desenvolvidas 
na interlocução e interação médico-paciente e as ferramentas para o aprimoramento da prática médica.

\section{MÉTODOS}

Trata-se de um estudo observacional, descritivo, com análise integrada de conteúdo. A amostra foi por conveniência, não probabilística, sendo composta por três grupos no total de 181 participantes: profissionais médicos $(\mathrm{n}=46)$, graduandos de Medicina da quinta e sexta séries $(\mathrm{n}=$ 54) e indivíduos surdos $(n=81)$. Estabeleceram-se os seguintes critérios de elegibilidade para cada grupo: 1. médicos: atuar profissionalmente na cidade de Maringá, no Paraná, independentemente do nível de atenção, serviço ou convênio (SUS, plano assistencial ou privado); 2. acadêmicos: estar devidamente matriculado na quinta ou sexta série do curso de Medicina de uma determinada instituição de ensino superior da mesma cidade e, portanto, atuantes em campos de estágio curricular do internato; 3. surdos: apresentar deficiência auditiva congênita, caracterizada por surdez parcial ou total desde o nascimento; e residir em Maringá.

A coleta foi realizada entre junho e outubro de 2018. Utilizaram-se dois instrumentos semiestruturados, um para médicos e internos e outro para surdos, elaborados pelos próprios autores, com base na literatura pertinente, constituído por duas seções. A primeira seção refere-se à caracterização dos participantes: sexo, idade, especialidade e tempo de atuação (no caso dos médicos) e escolaridade. A segunda seção é composta por questões objetivas e dissertativas orientadas aos dois grupos:

- Médicos/internos: questões sobre presença de acompanhante, sentimento durante a consulta, conhecimento de Libras, dificuldades na assistência aos surdos e estratégias de comunicação não verbal e Libras como ferramenta facilitadora para um atendimento de qualidade.

- Surdos: questões sobre conhecimento de Libras, necessidade de acompanhante, resistência à procura de atendimento por medo de incompreensão, dificuldades no atendimento, estratégias de comunicação utilizadas na consulta com o médico/interno, sentimento em consulta com profissional que desconhece Libras e propostas para aprimoramento da atenção à saúde dos surdos.

O contato dos participantes surdos foi realizado por meio de indicações da Associação dos Surdos de Maringá (Asumar) e por intermédio de uma professora de Libras, surda, a qual possuía contato com muitas pessoas com deficiência auditiva. Os participantes eram usuários exclusivos de Libras ou bilíngues intermodais, estes também chamados "surdos português-sinalizados", uma vez que sabem Libras e também são falantes do português.

Para entrevistá-los, houve a participação de um tradutor de Libras, sendo as entrevistas transcritas simultaneamente. Aos depoimentos relatados neste artigo, foram atribuídas as letras $\mathrm{I}, \mathrm{M}$ e $\mathrm{S}$ seguidas do número correspondente ao entrevistado para internos, médicos e surdos, respectivamente.

Realizou-se uma análise descritiva das variáveis quantitativas com distribuições percentuais para variáveis categóricas e medida de tendência central e dispersão para variáveis numéricas. Os dados obtidos das questões dissertativas foram analisados e organizados em três corpus textuais baseados nas seguintes questões:
- Corpus um: Como você, profissional médico, se sentiu perante o paciente surdo durante o atendimento?

- Corpus dois: Como você, interno de medicina, se sentiu perante o paciente surdo durante o atendimento?

- Corpus três: Como você, paciente, se sentiu ao ser atendido por um profissional com dificuldades de comunicação em Libras?

Em seguida, o material resultante foi submetido à análise lexicográfica com auxílio do software Interface de $R$ pour les Analyses Multidimensionnelles de Textes et de Questionnaires (IRaMuTeQ, em que se utilizou a modalidade de análise de similitude. Utilizou-se a declaração Strengthening the Reporting of Observational Studies in Epidemiology (Strobe) para revisão final do manuscrito ${ }^{15}$.

Este estudo seguiu todos os preceitos éticos de acordo com a Resolução no 466/2012 do Conselho Nacional de Saúde (Certificado de Apresentação para Apreciação Ética (CAAE) no 88254718.6.0000.5539).

\section{RESULTADOS}

Os resultados obtidos na pesquisa são referentes aos 181 participantes, entre os quais estão profissionais médicos de diferentes especialidades, internos do curso de Medicina e surdos com diferentes graus de perda auditiva. Nenhum dos participantes foi excluído.

Do total de pessoas surdas, $56,7 \%(46)$ eram do sexo feminino. O nível de escolaridade apresentado por 48,1\% (39) foi ensino médio completo, sendo o restante com nível superior. Em relação à modalidade de serviço de saúde, 43,2\% (35) mencionaram convênios, 39,5\% (32) citaram o SUS e 17,3\% (14) afirmaram que não possuem convênio de saúde e buscam atendimento particular. Dentre todos os entrevistados, 97,5\% (79) possuíam conhecimento de Libras, dos quais $80,2 \%$ (81) tinham conhecimento avançado da língua.

Os profissionais atuantes e internos entrevistados, em alguns momentos da análise, foram agrupados como "núcleo de medicina", no qual 46\% (46) eram médicos e os demais acadêmicos, sendo $53,7 \%$ (29) da quinta sériede Medicina e 38,9\% (21) do sexta, e 7,4\% (quatro) não responderam.

A média de idade é de $31,8( \pm 10,1)$ anos, prevalecendo o sexo feminino com $56 \%$ (56) dos entrevistados. No que se refere à modalidade de atendimento prestado, os profissionais médicos atendem pelo SUS (35\%), por convênio (30\%) e/ou atendimento particular (38\%). O tempo médio de atuação dos médicos é de 13,8 $( \pm 9,7)$ anos.

A maioria, 76\% (76), do núcleo de medicina afirmou já ter atendido um paciente com surdez parcial grave ou total, sendo 56,5\% (43) médicos e $43,5 \%$ (33) internos.

Em relação ao atendimento desses participantes, seis indivíduos do núcleo de medicina, sendo quatro (66,7\%) internos e dois $(33,3 \%)$ médicos, mencionaram que sentem desconfortáveis e inseguros quanto ao atendimento prestado; 49 indivíduos, 24 internos (49\%) e 25 médicos $(51,0 \%)$ médicos, afirmaram que, apesar do desconforto, mantiveram-se seguros quanto ao atendimento; 22 indivíduos do núcleo de medicina, sendo seis internos $(27,2 \%)$ e $16(72,7 \%)$ médicos, referiram que se sentem confortáveis e satisfeitos em relação ao atendimento; e 23 indivíduos (23\%) não responderam à questão.

O Gráfico 1 mostra as dificuldades encontradas durante o atendimento na visão do núcleo de medicina e dos participantes surdos. Para 58,7\% (37) dos médicos e 51,2\% (22) dos internos, a

REVISTA BRASILEIRA DE EDUCAÇ̃̃o MÉDICA

3 44 (4) : e121; 2020 


\section{Gráfico 1}

Distribuição percentual das dificuldades encontradas durante atendimento médico

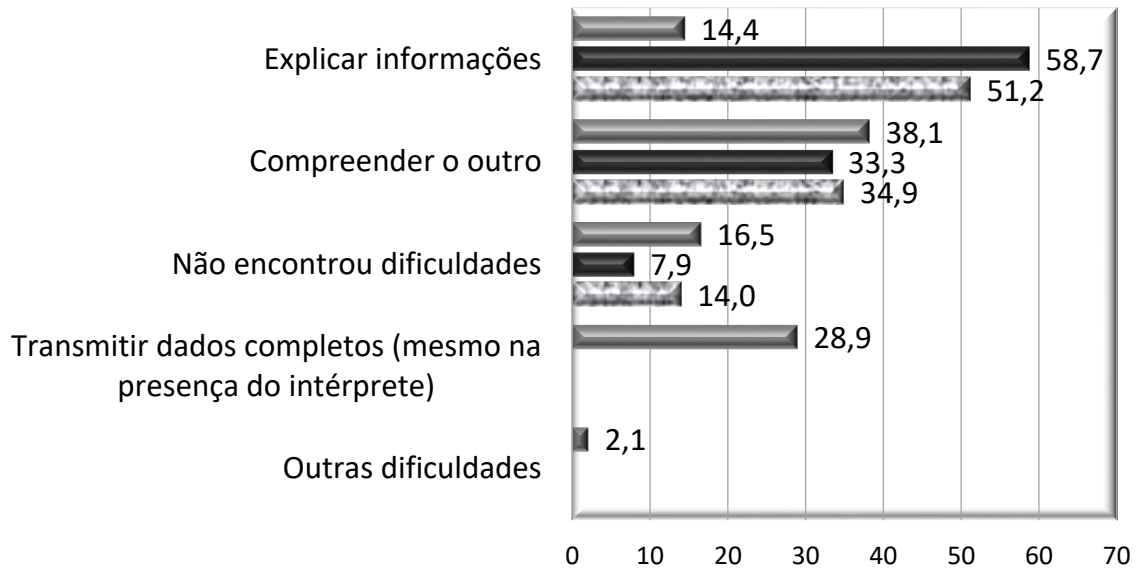

国 Surdo Médico $\square$ Interno

O item "Explicar informações" no contexto médico/interno diz respeito a explicar informações clínicas e de conduta de tratamento. Já em relação ao paciente surdo, diz respeito a explicar ao profissional suas queixas e sintomas.

Fonte: Elaborado pelos autores.

maior dificuldade relatada foi explicar informações sobre a doença, como plano terapêutico e esclarecimentos gerais. Em relação à dificuldade de compreender o outro, 33,3\% (21) dos médicos e 34,9\% (15) dos internos referiram dificuldades em compreender o paciente, e $38,1 \%$ (37) dos surdos afirmaram que têm dificuldade para compreender o profissional médico/interno.

Outras dificuldades foram descritas pelos surdos, como ter segurança no plano terapêutico proposto pelo profissional. Do total de surdos entrevistados, 55,5\% (45) afirmaram deixaram de ir ao médico por medo de não serem compreendidos ou relataram algum problema, como dor, desconforto ou angústia. Ainda, 72,8\% (59) referiram o costume de levar acompanhantes à consulta médica.

Apenas 16 indivíduos do núcleo de medicina, dez internos (62,5\%) e seis médicos (37,5\%), afirmaram ter algum conhecimento em Libras. Quando questionados se consideram que o conhecimento em Libras ampliaria significativamente a qualidade do atendimento aos surdos, 83 indivíduos do núcleo de medicina, responderam que sim 48 internos $57,8 \%(48)$ e 35 médicos (42,1\%) médicos; um indivíduo respondeu que não (médico); 15 afirmaram que talvez, cinco internos (33,3\%) e dez médicos (66,7\%); um indivíduo não respondeu. Sobre o momento ideal para que a capacitação para assistência ao surdo fosse incentivada durante a formação acadêmica, 35 sujeitos do núcleo de medicina, 22 internos (63\%) e 13 médicos (37\%13), posicionaram-se a favor da inclusão curricular da disciplina de Libras, enquanto 29 optaram pelo modo extracurricular (62\% (18) dos internos e 38\% (11) dos médicos). O restante acredita que $\mathrm{o}$ aprendizado deveria ocorrer durante o treinamento na vida profissional por iniciativa própria ou outros.

Os vocábulos mais presentes na resposta dissertativa sobre o sentimento do médico durante a assistência ao surdo (corpus um) estão apresentados na Figura 1, organizados em três núcleos centrais- sentir, paciente e dificuldade. A seguir apresentamos as falas representativas:
Desconfortável, insatisfeito por não conseguir toda a informação pretendida (M10).

Desconfortável por não conseguir entender completamente a história da doença contada pelo paciente (M26).

Desconforto em solicitar as medidas para realização do exame (M28).

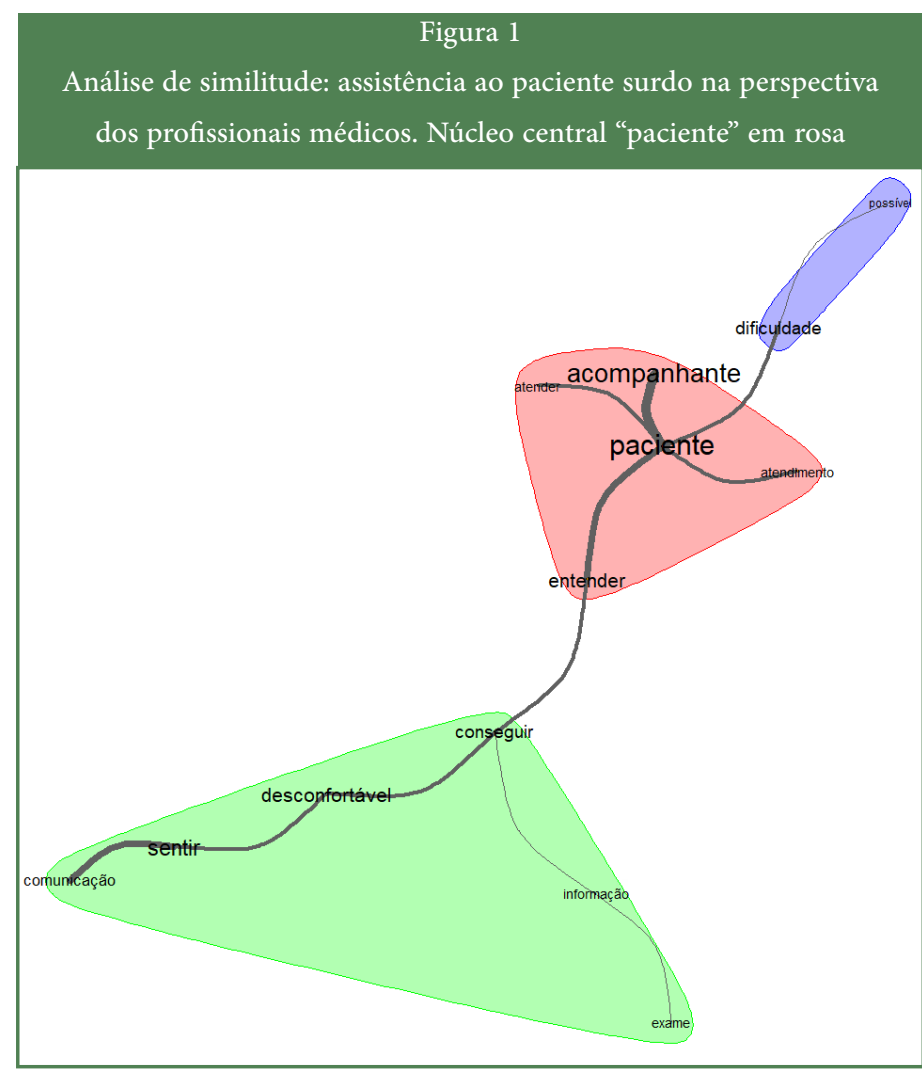

Fonte: Elaborada pelos autores.

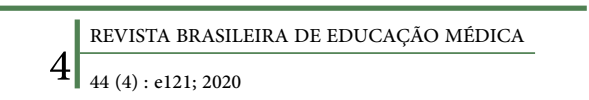


A Figura 2 apresenta o leque semântico das palavras mais frequentes na perspectiva do interno (corpus dois). Foram gerados cinco núcleos centrais: Libras, paciente, estar, atendimento e não. Observa-se que associadas ao núcleo atendimento estão as palavras acompanhante e comunicação, mostrando que o interno reconhece a necessidade de uma terceira pessoa para criar uma ponte de comunicação com seu paciente, uma falha importante na relação direta entre o profissional e o indivíduo com surdez.

É mais difícil criar uma relação médico-paciente devido essa barreira linguística. A comunicação acontece com maior frequência com o acompanhante e há obstáculos para passar e receber informações do paciente. Há uma certa insegurança se foi passado exatamente o que queria se dizer (I27).

No que se refere à perspectiva do surdo (corpus três), a Figura 3 apresenta os vocábulos mais prevalentes, os quais geraram um núcleo central - entender - relacionado a três núcleos periféricos, sendo os elementos mais frequentes: falar, saber e sentir..

Na perspectiva dos surdos, o núcleo central entender está relacionado fortemente aos núcleos difícil e preocupado, mostrando que o paciente se sente incompreendido durante a consulta médica.

O Gráfico 2 apresenta as estratégias utilizadas por médicos, internos e surdos para comunicação durante o atendimento. A presença de um acompanhante foi o recurso mais utilizado entre os entrevistados, correspondendo a $36,3 \%$ (33) para os médicos, $28,2 \%$ (20) para internos e $30 \%$ (24) para os surdos. A escrita foi mais utilizada entre os profissionais - 19,8\% (18) dos médicos e 19,7\% (14) dos internos - do que pelos surdos, 16,3\%(13). A Libras foi usada quase nove vezes mais pelos surdos do que por médicos e duas vezes mais pelos internos. A mímica foi mais utilizada pelos profissionais.

Quando indagados quanto a sugestões para melhorias dos serviços de assistência à saúde dos surdos, os participantes surdos compartilharam do anseio por profissionais de saúde com conhecimento mínimo em Libras ou ao menos a disponibilidade de um profissional habilitado nos serviços de urgência e emergência.

É necessário que médicos, enfermeiros e demais profissionais saibam o básico de Libras. Em situações de emergência, não há tempo para escrever ou para não conseguir se comunicar [...] (S16).

Fazer curso de Libras, participar de palestra sobre surdez e contratar um intérprete. Associação de Surdos da minha cidade tem dois intérpretes, é pouco mesmo. Prefeitura não contrata mais (S19).

\section{DISCUSSÃO}

Apesar de a maioria do núcleo de medicina exibir desconforto no atendimento do paciente surdo, a partir da fala seguinte, observa-se que alguns profissionais podem abordá-lo como qualquer outro indivíduo com dificuldade de comunicação: "Desconfortável, mesma sensação de quando encontro qualquer indivíduo de comunicação difícil" (M8).

Quando esse achado é contraposto à opinião dos participantes surdos sobre o atendimento, infere-se que alguns profissionais não detêm a real consciência das fragilidades da assistência ofertada:

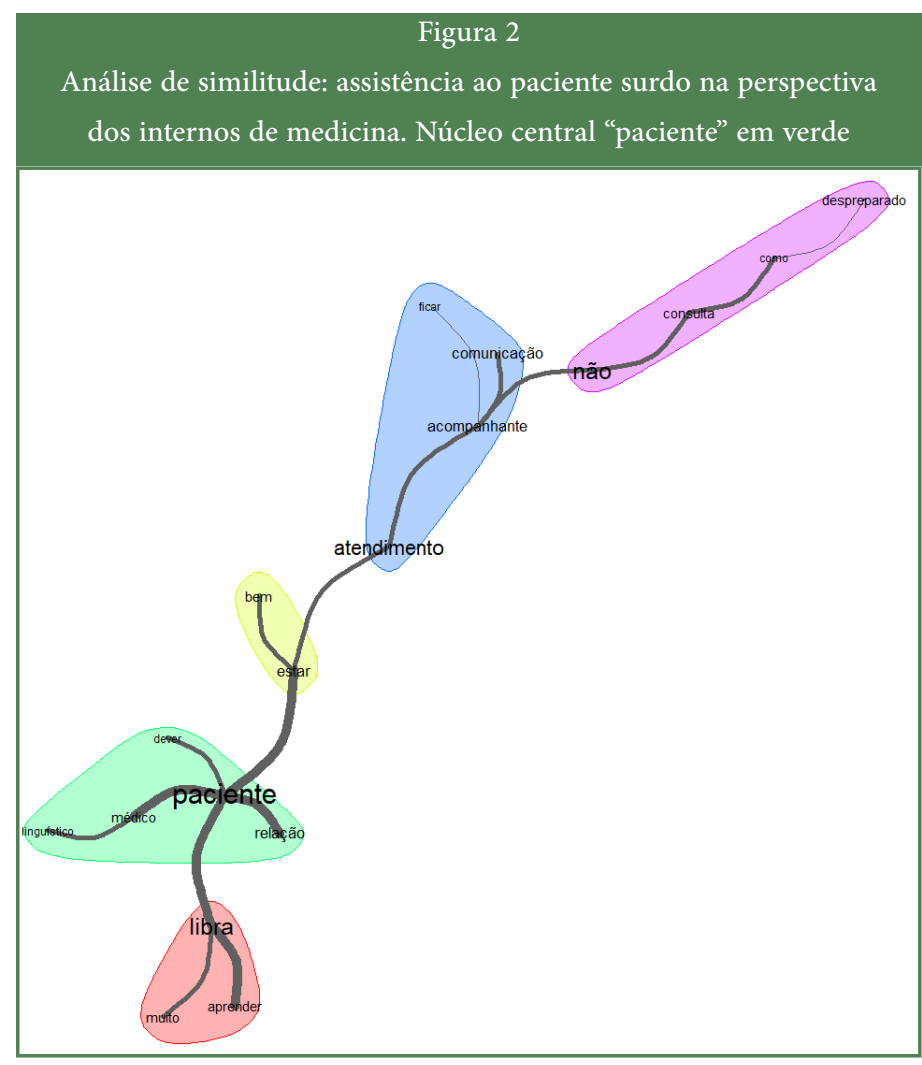

Fonte: Elaborada pelos autores.

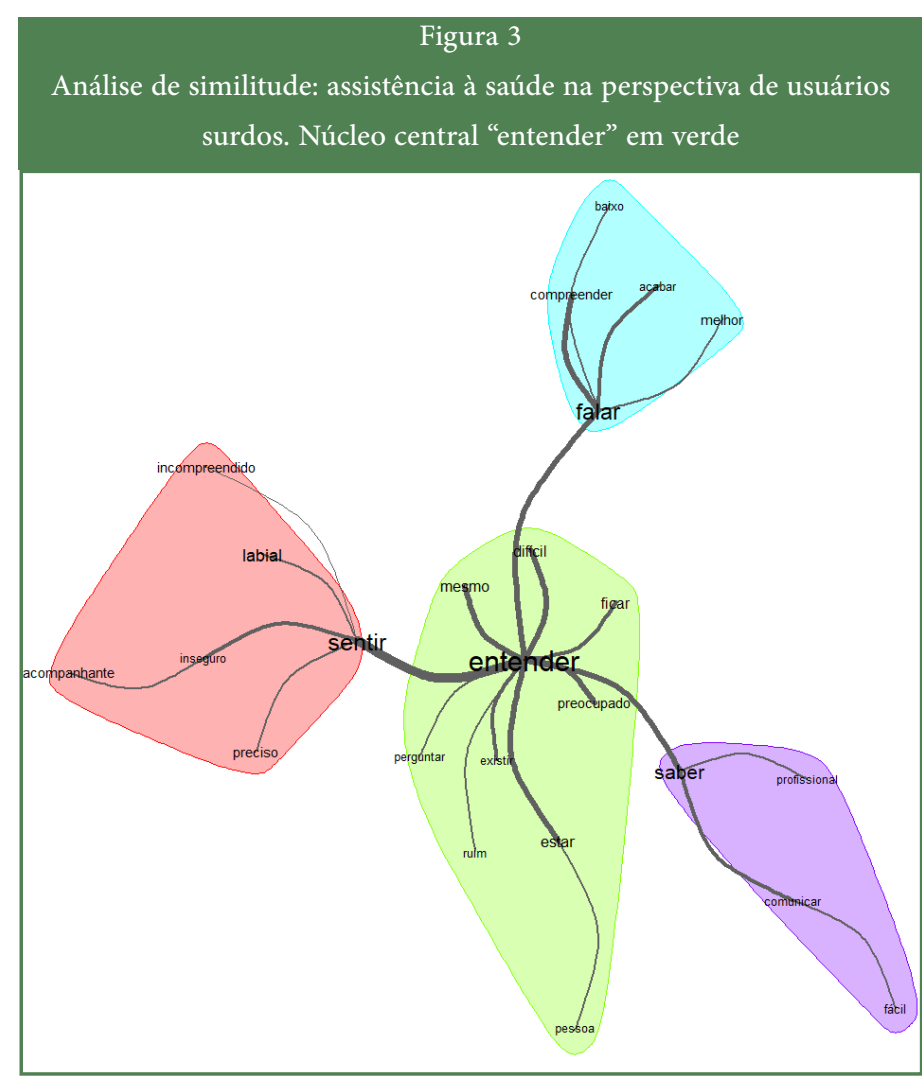

Fonte: Elaborada pelos autores. 


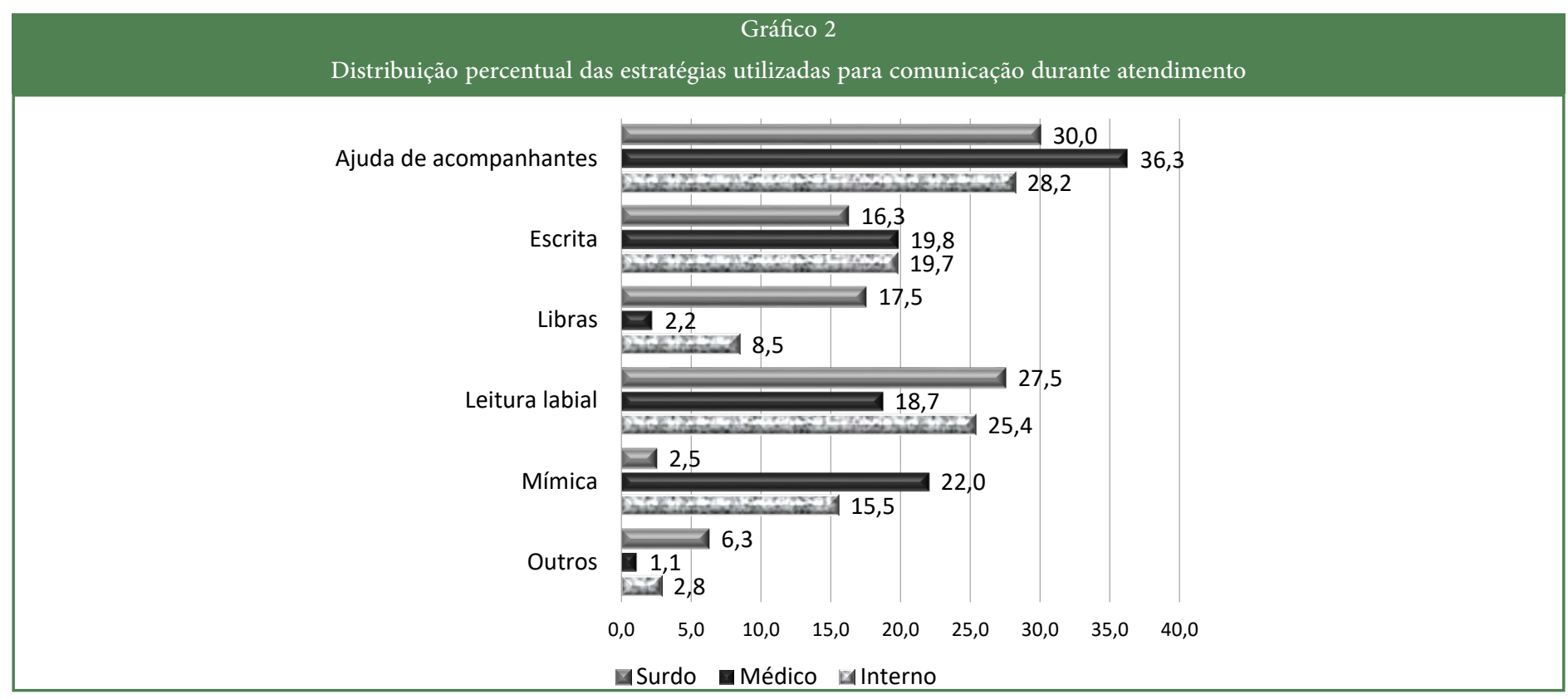

Fonte: Elaborado pelos autores.

Sinto-me angustiada, magoada e triste por não haver comunicação comigo. Preocupada se o médico entendeu mesmo o que estou sentindo e se vou melhorar. Existe uma barreira de comunicação, com pouco entendimento. Gostaria de ser tratada como os outros (S03).

Observa-se que alguns profissionais costumam não compreender as particularidades dos surdos. Escrever enquanto fala com o paciente, chamá-lo em voz alta de outra sala e mostrar-se impaciente ao precisar explicar melhor e mais devagar os medicamentos prescritos são atitudes que demonstram despreparo profissional ${ }^{10,16}$. Este transpassa o desconhecimento de Libras e permeia a incompreensão da identidade da pessoa surda e dos fatores culturais que caracterizam sua comunidade ${ }^{10}$.

A interação médico-paciente é constituída de processos psicossociais complexos e utiliza ferramentas verbais e não verbais para que ocorra uma troca de informações entre o médico e paciente ${ }^{17}$. Essa interação não se relaciona apenas com a satisfação durante a consulta, mas pode interferir no diagnóstico e na adesão ao plano terapêutico ${ }^{17}$.

Ao compararmos os elementos relacionados ao vocábulo paciente nos núcleos centrais gerados a partir de cada um dos grupos (Figuras 1 e 2), percebemos que, na visão dos médicos, o vocábulo acompanhante mostra-se tão frequente quanto o vocábulo paciente. Além disso, as falas representativas da Figura 1 (M10, M26 e M28) evocam a ideia de que a limitação do paciente dificulta e compromete o desenvolvimento de seu trabalho e o não atendimento pleno das necessidades do paciente. $\mathrm{Na}$ perspectiva dos acadêmicos, o médico deveria vencer a barreira linguística com o paciente para garantir um bom relacionamento.

O médico, como prestador de serviços na área da saúde, deve zelar não apenas por sua competência técnica, mas também pelo conhecimento aprofundado e pelas habilidades que favoreçam o estabelecimento de processos de comunicação e relações de caráter interpessoal ${ }^{4}$. Como verificado neste estudo, a barreira linguística na relação médico-paciente pode gerar frustração e insegurança.
Observa-se que a necessidade de vencer os desafios linguísticos e as dificuldades do exame clínico é percebida por médicos, internos e surdos, conforme evidenciado nas falas:

Necessidade de aulas de Libras e treinamento teórico-prático prévio. A surdez na relação médico-paciente não deve ser encarada como doença (a não ser que este seja o motivo da consulta) e sim como um obstáculo linguístico a ser vencido, devemos nós nos adaptar à sua realidade linguística (I15).

Despreparada. Não obtive, nunca, nenhum tipo de preparo para essa situação (I4).

Inicialmente, fiquei apreensiva, pois sabia que seria um desafio. Mas, com o decorrer do atendimento, percebi que estava transcorrendo relativamente tudo bem, que a comunicação não ficou comprometida usando o recurso de mímicas e ajuda de acompanhantes. Em um dos meus atendimentos envolvendo surdos, a paciente era gestante e estava em trabalho de parto. $O$ desafio foi ainda maior, mas deu tudo certo! (M16).

Assim como observado na Figura 3 e nas falas seguintes, o surdo sente-se inseguro durante a assistência, até mesmo com relação ao diagnóstico e tratamento proposto:

Me sinto para baixo, gostaria que os médicos conseguissem nos entender. Muitos de nós não sabem como escrever e não fazem leitura labial (S12).

Tem alguns médicos que falam muito baixo; mesmo que eu peça para falar um pouco mais alto ou articular melhor a boca, eles acabam esquecendo (S18).

Sinto dificuldade. É ruim saber que o profissional não entende o que eu tenho (S14). 
O médico pode entender qual o agravo, mas não consegue se fazer entender pelo paciente com surdez, o que pode levar ao manejo inadequado da doença e dificultar a adesão do paciente ao tratamento, pois ele não tem o total entendimento do que está acontecendo ${ }^{1}$. A comunicação superficial associada à falta de acompanhamento do desenvolvimento do caso passa aos médicos uma falsa impressão de que compreendem o paciente e resolvem o problema dele ${ }^{6}$.

A assistência à pessoa surda se insere no mesmo modelo assistencial geral utilizado pelos demais cidadãos, baseada nos princípios de integralidade, equidade e universalidade, como previsto na Constituição Federal de 1988 e na Lei no 8.080/90. Não deve existir nenhum tipo de diferenciação no atendimento que prejudique qualquer uma das partes. Assim, é de responsabilidade da atenção básica o desenvolvimento de práticas de cuidado à saúde direcionadas para os indivíduos que apresentem algum tipo de deficiência ${ }^{4}$.

Ademais, verificaram-se neste estudo, conforme as falas indicadas a seguir, relatos de percepções quanto às consequências do despreparo no atendimento a surdos em serviços terciários.

O médico confunde os locais que sinto dor (S10).

[...] em situações de emergência, não há tempo para escrever ou para não conseguir se comunicar. Erros de comunicação podem gerar consequências importantes. Por exemplo, estava com alergia, sem respirar, e o médico me deu uma injeção que piorou ainda mais o quadro, porque tenho alergia ao medicamento utilizado, mas o médico não me perguntou porque não conseguiu se comunicar (S16)

Conforme demonstrado na Gráfico 2, a participação do acompanhante é a estratégia mais utilizada de acordo com a opinião dos participantes. Contudo, contar com a presença de um acompanhante e delegar a ele a missão de garantir a comunicação entre médico e paciente merece importantes questionamentos.

$\mathrm{Na}$ visão dos surdos, observa-se uma dualidade quanto à presença de acompanhante nos atendimentos, e $72,8 \%$ (59) referiram levar alguém consigo nas consultas para facilitar a compreensão. Por um lado, identificou-se a necessidade do acompanhante para conferir segurança ao paciente, diante das recomendações médicas, assumindo papel de interlocutor durante a consulta, conforme demonstrado a seguir:

O médico não sabe conversar e tem medo de se comunicar com surdos. Às vezes, não tem paciência para conversar devagar (S14).

Levo meus familiares como intérpretes, porque tenho medo de fazer o tratamento de forma inadequada. Os médicos deveriam aprender Libras e respeitar os surdos (S15).

Algumas vezes procuro ajuda médica sem acompanhante, mas me sinto insegura porque não consigo entender nem os exames solicitados, nem a conduta a ser seguida. O doutor fala muito difícil. Na presença do acompanhante me sinto mais segura (S10).

Por outro lado, o acompanhante configura-se como um indivíduo que fragiliza a relação médico-paciente, principalmente quando envolve assuntos íntimos ou particulares:
Extremamente constrangido, pois tenho que expor meus problemas a uma pessoa que não é da área da saúde. E como fica a ética e o sigilo (S31).

Muitas vezes, o acompanhante não tem ética e fico com medo por não receber as informações direto do médico. Em doenças como Aids, seria melhor receber a notícia direto do médico (S40).

Uma das grandes premissas do atendimento humanizado e integral em saúde é a relação direta, sem atravessadores, entre profissional e paciente. Essa condição permeia um acolhimento efetivo e os princípios bioéticos dessa relação, respeitando a autonomia e tendo como foco o paciente, de forma integral ${ }^{12}$. Segundo o Código de Ética Médica ${ }^{18}$, capítulo IV, artigo 24: "é vedado ao médico deixar de garantir ao paciente o exercício do direito de decidir livremente sobre sua pessoa ou seu bemestar, bem como exercer sua autoridade para limitá-lo".

A leitura labial como estratégia de comunicação foi mais apontada pelos participantes surdos (Gráfico 2) do que entre internos e médicos. Além de exigir muita concentração, a leitura labial pode ser prejudicada significativamente pela presença de bigode, sotaque, mudanças de posição ou uso de máscaras ${ }^{19}$ : "Já sofri com médico idoso, gago e com bigode. Tive dificuldade de ler seus lábios por causa disso" (S17).

A língua escrita pode ser identificada como uma barreira ao acesso dos surdos ao serviço de saúde ${ }^{20}$, pois normalmente apresentam dificuldade com a língua portuguesa, uma língua secundária para eles, podendo gerar constrangimentos $^{10,13,19}$. Ademais, em situações mais complexas, como em casos de violência, transtornos mentais e/ou afecções que envolvem a sexualidade do paciente, quando se precisa detalhar a história , essa estratégia mostra-se menos eficaz, aumentando a possibilidade de erros de interpretação do caso ${ }^{13}$.

Em relação ao emprego de mímica durante as consultas, a estratégia foi muito mais utilizada por parte dos profissionais (Gráfico 2), talvez pelo fato de que os movimentos gestuais e as expressões faciais são passíveis de interpretação amplamente variável, podendo resultar em equívocos de compreensão, não sendo preferíveis por surdos ${ }^{19}$.

É unânime entre os estudos ${ }^{10,13,19}$, incluindo o presente, que a Libras ocupa a última posição entre as estratégias utilizadas pelos profissionais, reforçando que a inclusão dela na graduação médica é recente e rara.

Como descrito nos resultados, menos de um quinto do núcleo de medicina afirmou ter algum conhecimento em Libras, dado em consonância com revisão integrativa recente ${ }^{14}$ que constatou que os profissionais de saúde não possuem conhecimento básico de Libras e estão, em sua maioria, despreparados para atender eficazmente um paciente com surdez.

Não limitada à assistência à saúde, a verdadeira inclusão social do surdo depende do preparo da população para acolhê-lo e interagir de forma adequada. Assim, viabilizar acessibilidade requer não apenas capacitação, mas também conscientização da demanda dos pacientes surdos e da importância do cuidado individualizado e humano ${ }^{21}$.

Para os sujeitos desta e de outras pesquisas ${ }^{1}$, a comunicação por meio da Libras entre surdos e profissionais da saúde é considerada a forma mais adequada e humanizada de acolhimento. Os surdos entrevistados ressaltaram a necessidade de profissionais de saúde capacitados para comunicação em Libras, especialmente em cenários de urgência

REVISTA BRASILEIRA DE EDUCAÇÃO MÉDICA

7 44 (4) : e121; 2020 
e emergência, e externalizaram que se sentem mais confortáveis e respeitados quando atendidos por profissionais com conhecimento básico em língua de sinais: "Tem um médico que eu sempre consulto e que sabe Libras. Sinto-me bem quando posso me comunicar com Libras, bem fácil de entender sobre a doença e esclarecer minhas dúvidas sobre o tratamento" (S9).

A língua de sinais é parte da cultura e identidade da comunidade surda, logo deve ser reconhecida por todos os profissionais. Costa e Silva ${ }^{22}$ relatam que a inclusão de temas como esse parte de iniciativas individuais dos professores e ainda não conta com uma política das escolas médicas, $o$ que garantiria sua continuidade. Alguns estudos ${ }^{10,11,14}$ defendem a inserção da Libras na matriz curricular de todos os cursos de saúde, mas não foram encontradas publicações que aprofundem a discussão sobre as implicações da obrigatoriedade do ensino da disciplina. A Resolução $n^{\circ} 3$ do Conselho Nacional de Educação e da Câmara de Educação Superior (CNE/CES), de 20 junho de 2014, instituiu as Diretrizes Curriculares Nacionais do Curso de Graduação em Medicina e definiu que o futuro profissional de saúde deve apresentar uma comunicação que envolva aspectos verbais e não verbais e habilidades de escrita e leitura. Entretanto, de acordo com o Decreto $\mathrm{n}^{\circ}$ 5.626, de 22 de dezembro de 2005, a Libras deve ser ofertada, durante a graduação médica, como disciplina curricular optativa ${ }^{23}$.

Santos et al. ${ }^{16}$ propõem a adoção da disciplina de Libras por meio de metodologias ativas, com revisão teórico-prática dos conteúdos, de modo a aumentar o interesse pela disciplina e com a retenção do aprendizado. Contudo, o curso de Medicina dispõe de matriz curricular densa, e a implantação do curso de Libras na grade curricular obrigatória não garante que egresso permanecerá apto para comunicação na língua ao longo da vida profissional. $\mathrm{O}$ aprendizado de qualquer idioma requer dedicação e tempo ${ }^{6}$, sendo questionável seu potencial resolutivo como estratégia isolada. Nesse sentido, a disciplina poderia ser ofertada de modo optativo, estimulada pela validação de horas complementares em sua integralidade e/ou reconhecimento acadêmico a quem comprovar competência na comunicação em Libras.

A contratação de profissionais intérpretes como parte da equipe de saúde poderia auxiliar na consulta ${ }^{12}$, o que reduziria a necessidade de um acompanhante nas consultas e a inibição do paciente em relação a alguns assuntos. Contudo, apesar de não ser do convívio do paciente, ainda sim haveria a participação de uma terceira pessoa, o que não isenta o indivíduo de possíveis constrangimentos. Além disso, apenas disponibilizar intérpretes nos serviços de saúde não seria resolutivo, pois a ausência de formação apropriada dos intérpretes, o desconhecimento sobre a terminologia médica e a inexperiência dos servidores de saúde em atuar em conjunto com esses profissionais também deveriam ser alvo de intervenção ${ }^{24}$.

Por fim, uma recente revisão ${ }^{13}$ propõe, além de capacitações, novas estratégias de comunicação com o desenvolvimento de softwares e aplicativos móveis que explorem as linguagens visual e sonora ${ }^{13}$. O aplicativo Hand Talk pode converter em Libras textos, voz e até frases em placas de trânsito, e já foi empregado satisfatoriamente com uma gestante surda durante consultas de pré-natal com enfermeiro ${ }^{25}$.

Outras tecnologias, como o projeto "Giulia: mãos que falam", desenvolvido na Universidade Federal do Amazonas (UFAM), têm como objetivo captar, por meio de sensor, os movimentos da Libras e transmiti-los para um aparelho celular em forma de som, de modo a facilitar a comunicação e contribuir para a inclusão social das pessoas com deficiência auditiva ${ }^{26}$.

Contudo, Santos ${ }^{27}$ discute sobre a supervalorização das "tecnologias assistivas" como potenciais substitutos dos intérpretes humanos, uma vez que não conseguem transmitir sentimentos e significados valorativos.

\section{CONCLUSÕES}

Este estudo explorou a interação médico-paciente por meio das perspectivas de profissionais médicos, estudantes e surdos, todos dentro da mesma realidade em termos de assistência à saúde. Em suma, os profissionais médicos parecem não perceber integralmente as consequências da má comunicação para os indivíduos surdos, portandose mais distantes da dimensão dessa problemática e acreditando em desfechos positivos por meio de ferramentas comuns a quaisquer dificuldades de comunicação. Os internos mostraram-se mais sensíveis ao sofrimento dos surdos, externalizando certa insegurança e preocupação com o atendimento e a satisfação desses indivíduos. Talvez isso se deva ao emprego de metodologias ativas de ensino que privilegiam a interação do acadêmico com pacientes e profissionais de saúde desde o início de sua formação, levando-os a experienciar diversas situações reais de vulnerabilidade e fortalecendo o olhar empático e ético-humanístico. Por fim, a partir dos depoimentos dos surdos, foi possível constatar a complexidade do cenário de atendimento e as implicações negativas sobre a relação médico-paciente e sobre o bem-estar do indivíduo.

Este estudo reforça que, para assegurar a real acessibilidade do usuário surdo aos serviços de saúde, em todos os níveis de atenção é imperativo que seja feito um planejamento multimodal, com incentivo ao desenvolvimento de competência em Libras, contratação de intérpretes qualificados para a assistência em serviços de saúde, inclusão e familiarização com tecnologias digitais para interpretação/tradução entre Libras e português.

\section{AGRADECIMENTOS}

Agradecemos a Bruna Elisa Bührer e Marília Ignatius Nogueira Carneiro a contribuição na idealização do projeto de pesquisa e o auxílio na coleta de dados, respectivamente.

\section{REFERÊNCIAS}

1. Lopes RM, Vianna NG, Silva EM. Comunicação do surdo com profissionais de saúde na busca da integralidade. Saúde e Pesquina. 2017;10(2):213-21.

2. Dias AR, Coutinho CR, Gaspar DR, Moeller L, Mamede M. Libras na formação médica: possibilidade de quebra da barreira comunicativa e melhora na relação médico-paciente surdo. Rev Med (São Paulo). 2017;96(4):209-14.

3. Silva RP, Almeida MAPT. Relação comunicativa entre o profissional de saúde e os surdos: uma revisão bibliográfica. Id Line Rev Psic. 2017;11(37):65368.

4. Sousa EM, Almeida MAPT. Atendimento ao surdo na atenção básica: perspectiva da equipe multidisciplinar. Id Line Rev Psic. 2017;10(33):72-82.

5. Instituto Brasileiro de Geografia e Estatística. Características gerais da população, religião e pessoas com deficiência do Censo Demográfico 2010 [acesso em 22 jul 2020]. Disponível em: https://www.ibge.gov. 
br/estatisticas/sociais/populacao/9662-censo-demografico-2010. html ?edicao $=9749 \& \mathrm{t}=$ sobre .

6. Gomes LF, Machado FC, Lopes MM, Oliveira RS, MedeirosHolanda B, Silva LB, et al. Conhecimento de Libras pelos médicos do Distrito Federal e atendimento ao paciente surdo. Rev Bras Educ Med. 2017;41(4):390-6 [acesso em 22 jul 2020]. Disponível em: http://www.scielo.br/scielo.php?script=sci_arttext\&pid=S0100$55022017000400551 \& \operatorname{lng}=$ pt\&tlng $=$ pt.

7. Levino DA, Souza EB, Cardoso PC, Silva AC, Carvalho AETM. Libras na graduação médica: o despertar para uma nova língua. Rev Bras Educ Med. 2013;37(2):291-7.

8. BRASIL. Decreto $\mathrm{n}^{0} 5.626$, de 22 de dezembro de 2005. Regulamenta a Lei $\mathrm{n}^{\circ} 10.436$, de 24 de abril de 2002, que dispõe sobre a Língua Brasileira de Sinais (Libras), e o art. 18 da Lei ${ }^{\circ}$ 10.098, de 19 de dezembro de 2000. Brasila; 2005.

9. Nóbrega JD, Munguba MC, Pontes RJS. Atenção à saúde e surdez: desafios para implantação da rede de cuidados à pessoa com deficiência. Rev Bras Promoç Saúde. 2017;30(3):1-10.

10. Araújo AM, Cotta BSS, Souza ACCR, Oliveira AP, Lages KS. A dificuldade no atendimento médico às pessoas surdas. Rev Interdiscip Ciências Médicas. 2019;3(1):3-9.

11. Santos A, Portes A. Percepções de sujeitos surdos sobre a comunicação na atenção básica à saúde. Rev Latino-Am Enferm. 2019;27:1-9.

12. Souza MFNS, Araújo AMB, Sandes LFF, Freitas DA, Soares WD, Vianna RS de M, et al. Principais dificuldades e obstáculos enfrentados pela comunidade surda no acesso à saúde: uma revisão integrativa de literatura. Rev CEFAC. 2017;19(3):395-405.

13. Albuquerque AKR, Sobrinho JLG. Dificuldades na comunicação com portadores de deficiência auditiva [trabalho de conclusão de curso]. Brasília: Centro Universitário do Planalto Central Apparecido dos Santos; 2018.

14. Lima RFF, Lima RF. Comunicação com o deficiente auditivo: dificuldades na prática do profissional da saúde. GEPNEWS. 2019;2(2):375-82.

15. Malta M, Cardoso LO, Bastos FI, Magnanini MMF, Silva CMFP da. Iniciativa Strobe: subsídios para a comunicação de estudos observacionais. Rev Saúde Pública. 2010;44(3):559-65.

16. Santos HV, Dosea GS, Andrade ME. Importância da utilização das metodologias ativas no ensino da Libras para profissionais da saúde. XI Encontro Internacional de Educação e Comunicação. Aracaju: Universidade Tiradentes.2018.

17. Bucker LCG, Franco LS, Leão MOGC, Oliveira MR, Higino SM, Mello DR., et al. Comunicação Acessível na Relação Médico-Paciente Durante a Anamnese. Rev Interdiscip do Pensamento Científico. 2018;4(1):133-42.

18. Conselho Federal de Medicina. Código de Ética Médica: Resolução CFM n 2.217, de 27 de setembro de 2018 , modificada pelas Resoluções CFM nº 2.222/2018 e 2.226/2019. Brasília; 2018. p. 1-12.
19. Britto FR, Samperiz MMF. Dificuldades de comunicação e estratégias utilizadas pelos enfermeiros e sua equipe na assistência ao deficiente auditivo. Einstein 2010;8(1):80-5 [acesso em 22 jul 2020]. Disponível em: http://www.scielo.br/scielo.php?script=sci arttext\&pid=S1679-45082010000100080\&lang=pt.

20. Pires HF, Almeida MAPT. A percepção do surdo sobre o atendimento nos serviços em saúde. Rev Enferm Contemp. 2016;5(1):68-77.

21. Moura CMAB, Leal MEA. Libras na saúde: ensino da Língua Brasileira de Sinais para acadêmicos e profissionais da saúde. Rev Práticas em Extensão. 2019;3(1):2-7.

22. Costa LSM, Silva NCZ. Desenvolvendo atitudes, conhecimentos e habilidades dos estudantes de medicina na atenção em saúde de pessoas surdas. Interface Comun Saúde Educ 2012;16(43):1107-17 [acesso em 22 jul 2020]. Disponível em: http://www.scielo.br/scielo. php?script=sci_arttext\&pid=S1414-32832012000400019.

23. Brasil. Diretrizes Curriculares Nacionais do Curso de Graduação em Medicina. Brasília: Ministério da Educação; 2014.

24. Queiroz M. Panorama da interpretação em contextos médicos no Brasil: perspectivas. Tradterm. 2014;23:193-223.

25. Saraiva FJC, Moura RS, Santos RFM. A voz das mãos: o uso do aplicativo Hand Talk na consulta de pré-natal com uma gestante surda. Anais do VI Encontro Alagoano de Educação Inclusiva/I Encontro Nordestino Inclusão na Educação Superior; 2015. Maceió: Universidade Federal de Alagoas; 2015.

26. Teixeira GS, Silva JA, Bilharva M, Schumacher TA, Avila CL. Libras: Língua Brasileira de Sinais. Centro Universitário Leonardo da Vinci; 2016. [Indaial, SC]

27. Santos RG. Aplicativos de Libras, problema ou solução? Artefactum: Rev Estud em Ling e Tecnol. 2017;(1):1-16.

\section{CONTRIBUIÇÃO DOS AUTORES}

Antonio Augusto Claudio Pereira participou da escrita do projeto, da coleta de dados, da revisão bibliográfica e da escrita do artigo. Nayara De Paula Passarin participou da escrita do projeto, da coleta de dados, da revisão bibliográfica, do processamento dos dados com o software IRaMuTeQ e da escrita do artigo. Fernanda Shizue Nishida participou da análise estatística, da análise dos resultados e da escrita do artigo. Valéria Ferreira Garcez participou da escrita do projeto, da análise dos dados e da escrita do artigo.

\section{CONFLITO DE INTERESSES}

Os autores declaram não haver conflito de interesses neste estudo.

\section{ENDEREÇO PARA CORRESPONDÊNCIA}

Valéria Ferreira Garcez. Avenida Guedner, 1610, Maringá, PR, Brasil. CEP: 87050-390.

E-mail: valeria.garcez@gmail.com 